\title{
PENERAPAN DATA MINING UNTUK ANALISIS POLA BELANJA KONSUMEN MENGGUNAKAN ALGORITMA APRIORI PADA MALL CPM JAKARTA
}

\author{
Persis Haryo Winasis \\ Mahasiswa Program Pascasarjana Magister Ilmu Komputer \\ Universitas Budi Luhur \\ Email: persis.winasis@gmail.com
}

\begin{abstract}
Companies engaged in retail such as malls that have a lot of transaction data and sales transactions that are very much. Every purchase transaction made by consumers will be recorded and purchased in one database. Processing data in this study was carried out using a priori algorithm and using the help of the Weka application. The results of data mining in this study are expected to be able to produce new information about spending patterns in a certain period that can be used by the mall manager and store manager to support each related product promotion or organizing an event to increase the number of consumers in a certain period.
\end{abstract}

Keywords: apriori algorithm, data mining, shopping pattern analysis.

\section{PENDAHULUAN}

Persaingan perusahaan yang bergerak dibidang retail seperti mall di Indonesia khususnya di kota besar seperti di Jakarta menuntut pihak pengelola mall untuk bisa menemukan strategi agar mampu terus menerus menarik minat pengunjung untuk datang dan berbelanja di toko yang ada. Keberlangsungan banyaknya transaksi penjualan dari masing masing toko juga tidak terlepas dari peran aktif pihak pengelola mall untuk bisa memberikan tawaran promosi maupun acara acara yang diadakan di dalam mall. Konsumen atau pengunjung cenderung akan lebih memilih berbelanja di suatu mall yang bisa memberikan penawaran promosi yang sesuai dengan kebutuhan konsumen saat ini. Analisis terhadap data transaksi mampu memberikan informasi mengenai pola belanja konsumen di dalam suatu mall dalam periode tertentu. Analisis mengenai toko apa saja yang sering dikunjungi dalam satu waktu yang sama oleh seorang konsumen dengan menggunakan aturan asosiasi dan algoritma apriori 
berfungsi untuk menemukan kombinasi yang mungkin terjadi. Nantinya kombinasi tersebut akan diuji apakah memenuhi nilai ambang yang sudah ditentukan melalui parameter minimum support dan minimum confidence. Tujuan dari analisis tersebut adalah mendapatkan informasi mengenai pola belanja konsumen dalam suatu mall, sehingga informasi tersebut bisa digunakan pihak pengelola mall maupun penjual sebagai pertimbangan dalam menentukan promosi barang maupun acara yang perlu diselenggarakan untuk meningkatkan penjualan.

\section{TINJAUAN PUSTAKA}

\section{Data Mining}

Data Mining merupakan proses untuk menggali nilai tambah berupa informasi yang selama ini belum didapatkan secara manual dari suatu database. Data mining menggali pola-pola dari data untuk dimanipulasi menjadi sebuah informasi baru yang diperoleh dengan cara mengekstraksi dan mengenali pola yang penting atau menarik (Apostolakis, 2010) (gsbipb, 2013).

Data mining memiliki beberapa fungsi yang paling umum, fungsi tersebut adalah (Larose, 2005) (Muchlisin Riadi, n.d.):

a. Description

Tujuan deskripsi adalah mengidentifikasi pola yang muncul secara berulang dari suatu data serta kemudian mengubah pola menjadi aturan dan kriteria yang mudah dimengerti.

b. Clasification

Merupakan proses menemukan model atau fungsi yang mendeskripsikan dan membedakan data ke dalam kelas-kelas. Klasifikasi melibatkan proses pemeriksaan karakteristik objek dan memasukkan objek ke dalam salah satu kelas yang sudah didefinisikan sebelumnya. 


\section{c. Prediction}

Prediksi hamper sama dengan klasifikasi, namun data diklasifikasikan berdasarkan perilaku atau nilai yang diperkirakan pada masa yang akan datang.

\section{d. Estimation}

Pada fungsi estimasi, model dibuat menggunakan record lengkap yang menyediakan nilai dari variabel target sebagai nilai prediksi. Selanjutnya pada pemeriksaan berikutnya, estimasi nilai dari variabel target dibuat berdasarkan nilai variabel prediksi.

e. Clustering

Tujuan clustering adalah untuk menghasilkan kelompok objek yang mirip satu sama lain dalam beberapa kelompok yang ada. Semakin besar kemiripan objek dalam suatu cluster dan semakin besar perbedaan tiap cluster maka kualitas analisis cluster akan semakin baik.

f. Association

Dalam dunia bisnis lebih umum disebut analisis keranjang belanja. Tugas asosiasi dalam data mining adalah menemukan atribut yang muncul dalam suatu waktu. Selain itu tugas dari asosiasi adalah berusaha untuk mengungkap aturan untuk mengukur hubungan antara dua atau lebih atribut.

\section{Algoritma Apriori}

Algoritma apriori digunakan untuk mendapatkan aturan asosiasi dan mencari pola hubungan antar satu atau lebih item dalam suatu data (INFORMATIKALOGI, 2017). Salah satu tahap analisis asosiasi yang menarik perhatian banyak peneliti untuk menghasilkan algoritma yang efisien adalah analisis pola frekuensi (frequent pattern mining). Suatu asosiasi dapat diketahui penting atau tidak dapat diukur menggunakan parameter support dan confidence. Support atau nilai penunjang adalah ukuran yang menunjukkan tingkat dominasi suatu item dari keseluruhan transaksi, 
sedangkan confidence atau nilai kepastian adalah kuatnya hubungan antaritem dalam aturan asosiasi (Kusrini, 2009).

\section{Analisis Pola Frekuensi}

Analisis ini dilakukan untuk mencari kombinasi item yang memenuhi syarat minimum dari nilai support dalam database. Nilai support dengan menggunakan satu buah item diperoleh dengan menggunakan rumus berikut:

$$
\operatorname{support}(A)=\frac{\text { jumlahtransaksimengandung } A}{\text { totaltransaksi }}
$$

Sedangkan untuk nilai support dengan dua buah item dapat diperoleh menggunakan rumus berikut:

$$
\begin{gathered}
\operatorname{suppotr}(A, B)=P(A \cap B) \\
\operatorname{support}(A, B)=\frac{\sum \text { transaksimengandungAdan } B}{\sum \text { transaksi }}
\end{gathered}
$$

\section{Aturan Asosiasi}

Setelah semua pola frekuensi tinggi ditemukan, langkah berikutnya adalah dicari aturan asosiasi yang memenuhi syarat minimum untuk confidence dengan menghitung confidence aturan asosiatif $\mathrm{A}-\mathrm{B}$ menggunakan rumus berikut:

$$
\begin{aligned}
& \text { confidence }=P(B \mid A) \\
& =\frac{\sum \text { transaksi mengandung } A \text { dan } B}{\sum \text { transaksi mengandung } A}
\end{aligned}
$$

Nilai yang dihasilkan kemudian diurutkan berdasarkan support dan confidence guna menentukan aturan asosiasi yang akan dipilih. Aturan diambil sebanyak "n" aturan yang memiliki hasil atau nilai terbesar. 


\section{METODE PENELITIAN}

\section{Pengumpulan Data}

Mall CPM memiliki sekitar 500 toko didalamnya. Jumlah transaksi setiap hari mencapai ratusan bahkan ribuan transaksi penjualan. Data yang digunakan dalam penelitian ini adalah data transaksi penjualan periode 1 Juli 2019 sampai dengan 7 Juli 2019. Data tersebut diperoleh dari database aplikasi membership yang digunakan untuk melakukan pendataan transaksi penjualan pada mall CPM. Data tersebut kemudian diolah untuk mendapatkan jumlah kemunculan toko dalam periode tertentu.

\section{Pengolahan Data Menggunakan Algoritma Apriori}

Pengolahan data dilakukan dengan akumulasi transaksi penjualan pada mall CPM dalam periode yang sudah ditentukan dan kemudian dilakukan pencarian nilai menggunakan algoritma apriori. Tahapan yang dilakukan dalam algoritma apriori terdiri dari beberapa tahap, yaitu:
a. Menentukan nilai dari minimum support dari setiap item yang ada.
b. Menentukan nilai dari minimum support untuk 2 item set.
c. Menentukan nilai dari minimum confidence.
d. Proses pembentukan aturan asosiasi.
Dalam proses penbentukan aturan asosiasi, peneliti menggunakan bantuan aplikasi Weka versi 38.

\section{HASIL DAN PEMBAHASAN}

\section{Pengumpulan Data}

Pada penelitian ini proses pengolahan data dilakukan dengan data yang sudah diekspor kedalam bentuk tabel Microsoft Excel. Pengolahan data menggunakan data transaksi selama 1 minggu. Dari data tersebut didapatkan total sebanyak 3.304 data transaksi penjualan yang kemudian diolah kembali dengan cara mengambil 10 toko dengan penjualan teratas selama 1 mingg. Dari total 10 toko dengan peringkat penjualan teratas tersebut didapatkan jumlah data transaksi sebanyak 407 data. 


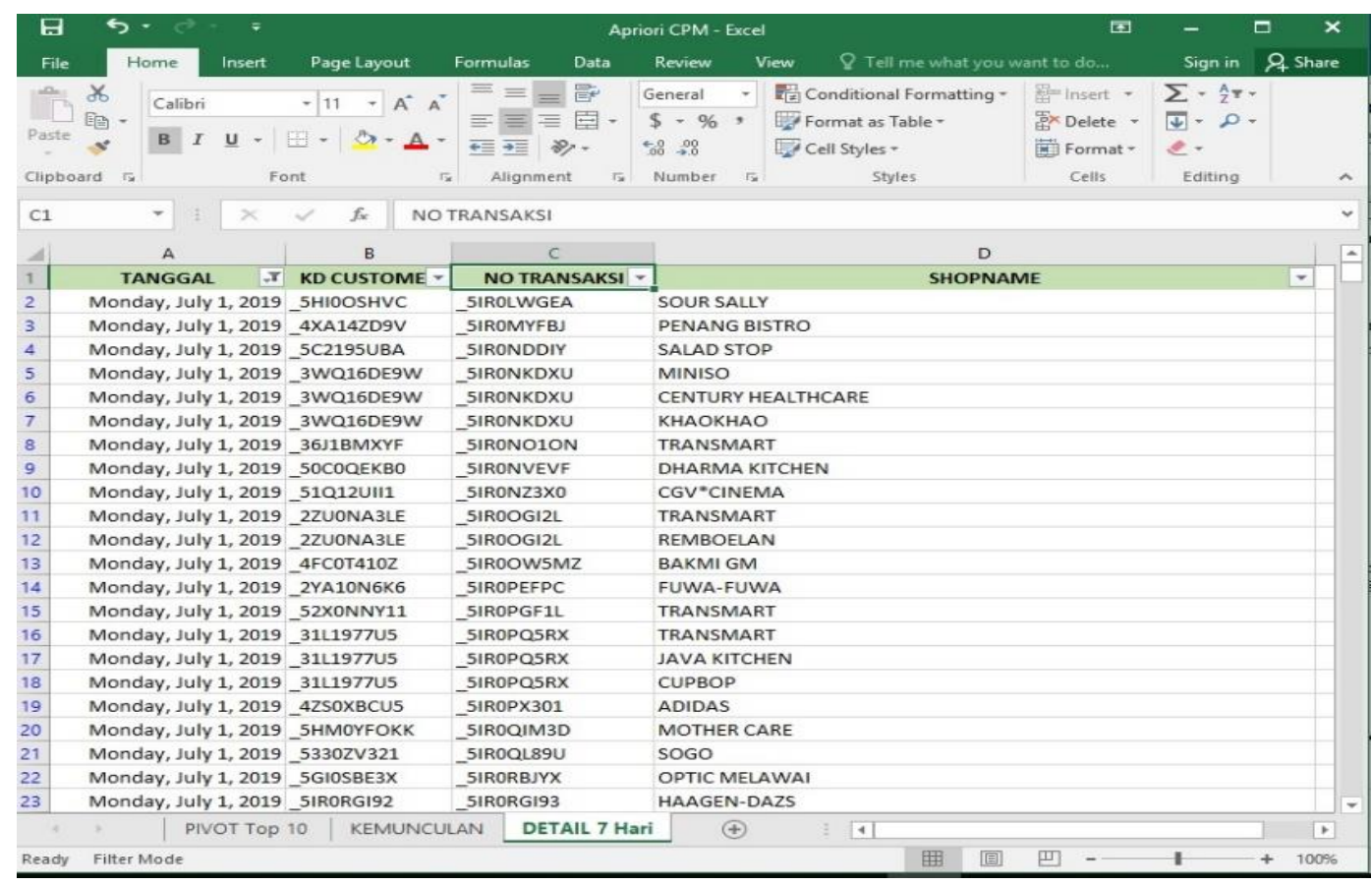

Gambar 1. Data transaksi penjualan dalam kurun waktu 1 minggu.

\section{Analisis Pencarian Pola Frekuensi Tertinggi}

Pada tahapan ini akan dilakukan proses pembentukan 1 itemset atau disebut C1. Pada proses ini data akan diolah menggunakan rumus sebagai berikut:

$$
\operatorname{support}(A)=\frac{\text { jumlahtransaksimengandung } A}{\text { totaltransaksi }}
$$

Dari rumus diatas, maka akan didapat data support dari masing masing item sebagai berikut:

Tabel 1. Data support itemset

\begin{tabular}{|l|l|l|l|}
\hline No & Nama Toko & Count & Support (\%) \\
\hline 1 & TRANSMART & 319 & $78.38 \%$ \\
\hline 2 & ACEHOMECENTER & 250 & $61.43 \%$ \\
\hline 3 & GRAMEDIA & 198 & $48.65 \%$ \\
\hline 4 & URBANKITCHEN & 174 & $42.75 \%$ \\
\hline 5 & SOGO & 140 & $34.40 \%$ \\
\hline 6 & ZARA & 124 & $27.27 \%$ \\
\hline 7 & H\&M & 49 & $12.04 \%$ \\
\hline 8 & CGV ${ }^{*}$ INEMA & 48 & $11.79 \%$ \\
\hline 9 & SUSHITEI & 36 & $8.85 \%$ \\
\hline 10 & STARBUCKS & 32 & $7.86 \%$ \\
\hline
\end{tabular}


Langkah berikutnya, berdasarkan tabel 1 akan dicari nilai yang memenuhi nilai minimum support yang telah ditentukan yaitu $\geq 30 \%$, maka akan didapat data yang tercantum didalam tabel berikut:

Tabel 2. Data support itemset dengan nilai minimum support $\geq 30 \%$

\begin{tabular}{|l|l|l|l|}
\hline No & Nama Toko & Count & Support (\%) \\
\hline 1 & TRANSMART & 319 & $78.38 \%$ \\
\hline 2 & ACEHOMECENTER & 250 & $61.43 \%$ \\
\hline 3 & GRAMEDIA & 198 & $48.65 \%$ \\
\hline 4 & URBANKITCHEN & 174 & $42.75 \%$ \\
\hline 5 & SOGO & 140 & $34.40 \%$ \\
\hline
\end{tabular}

Proses selanjutnya adalah melakukan pembentukan nilai 2 itemset atau C2 dengan cara melakukan kombinasi dari itemset yang sudah terbentuk sebelumnya. Pengolahan data dengan 2 itemset dilakukan dengan menggunakan rumus sebagai berikut:

$$
\begin{gathered}
\operatorname{suppotr}(A, B)=P(A \cap B) \\
\operatorname{support}(A, B)=\frac{\sum \text { transaksimengandungAdan } B}{\sum \text { transaksi }}
\end{gathered}
$$

Dari pengolahan data tersebut diatas maka akan menghasilkan nilai 2 itemset seperti tertera didalam tabel berikut ini:

Tabel 3. Data support 2 itemset

\begin{tabular}{|c|l|c|c|}
\hline Kode Join & \multicolumn{1}{|c|}{ Nama Toko } & Count & $\begin{array}{c}\text { Support } \\
(\mathbf{\%})\end{array}$ \\
\hline A & $\begin{array}{l}\text { TRANSMART, } \\
\text { ACEHOMECENTRE }\end{array}$ & 221 & $54.30 \%$ \\
\hline B & TRANSMART, GRAMEDIA & 183 & $44.96 \%$ \\
\hline C & TRNASMART, URBANKITCHEN & 148 & $36.36 \%$ \\
\hline D & TRANSMART, SOGO & 102 & $25.06 \%$ \\
\hline E & ACEHOMECENTER, GRAMEDIA & 170 & $41.77 \%$ \\
\hline F & ACEHOMECENTER, & 114 & $28.01 \%$ \\
\hline G & URBANKITCHEN & 51 & $12.53 \%$ \\
\hline H & ACEHOMECENTER, SOGO & 96 & $23.59 \%$ \\
\hline I & GRAMEDIA, URBANKITCHEN & 46 & $11.30 \%$ \\
\hline J & GRAMEDIA, SOGO & 49 & $12.04 \%$ \\
\hline
\end{tabular}




\section{Pembentukan Aturan Asosiasi}

Kemudian untuk mencari nilai confidence dan aturan asosiasi yang dibutuhkan kita dapat menggunakan bantuan aplikasi Weka versi 38. Sebelumnya perlu disiapkan terlebih dahulu data tabular yang nantinya akan di uanggah kedalam aplikasi Weka. Data tabular yang dimaksud dapat dilihat pada gambar 2 dibawah ini:

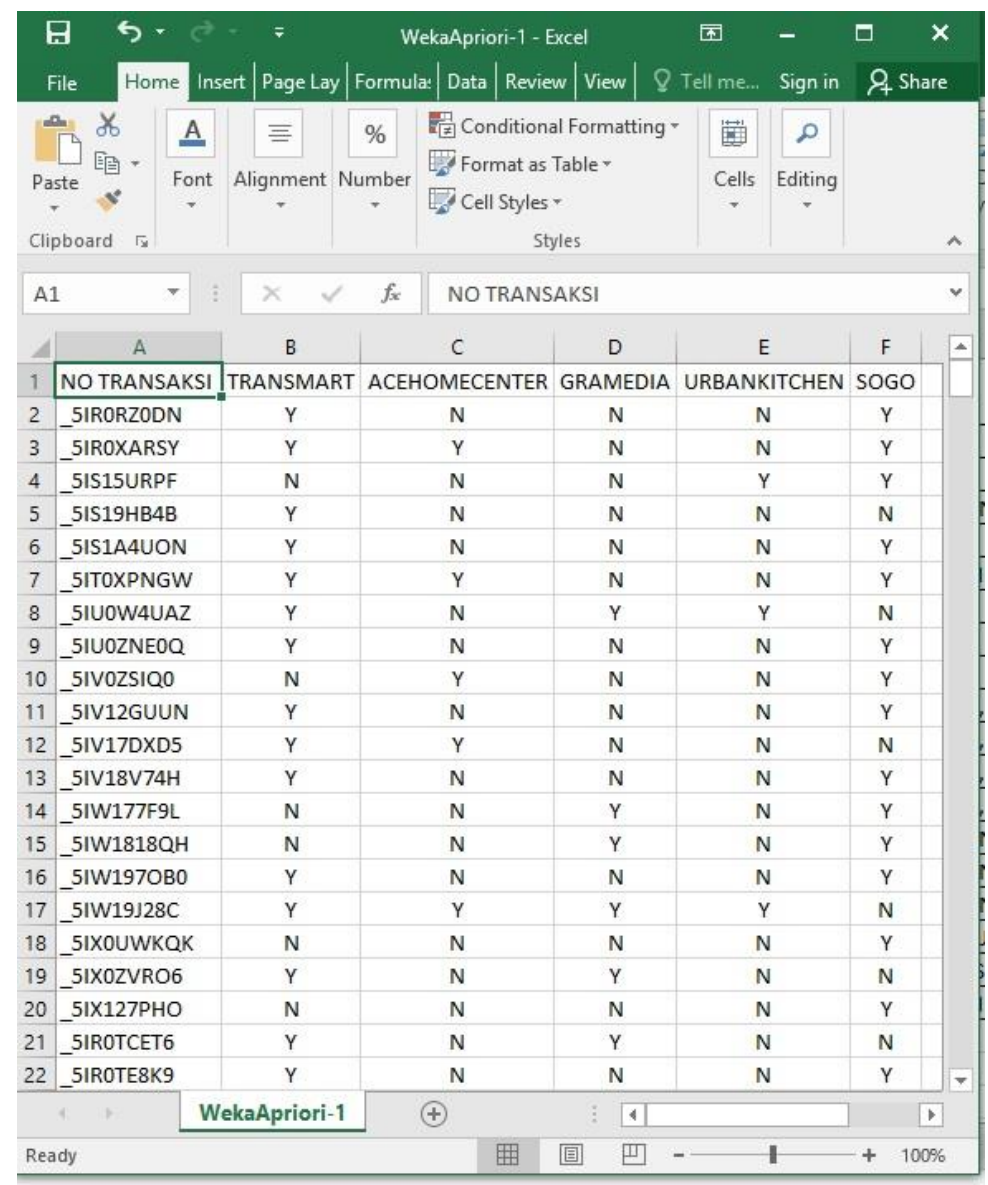

Gambar 2. Data tabular

Dalam proses pembentukan aturan asosiasi menggunakan aplikasi Weka, parameter nilai minimum support maupun nilai confidence dapat diatur sesuai dengan kebutuhan pengolahan data. Implementasi pengolahan data menggunakan aplikasi Weka dapat dilihat pada gambar 3 dan 4 dbawah ini: 


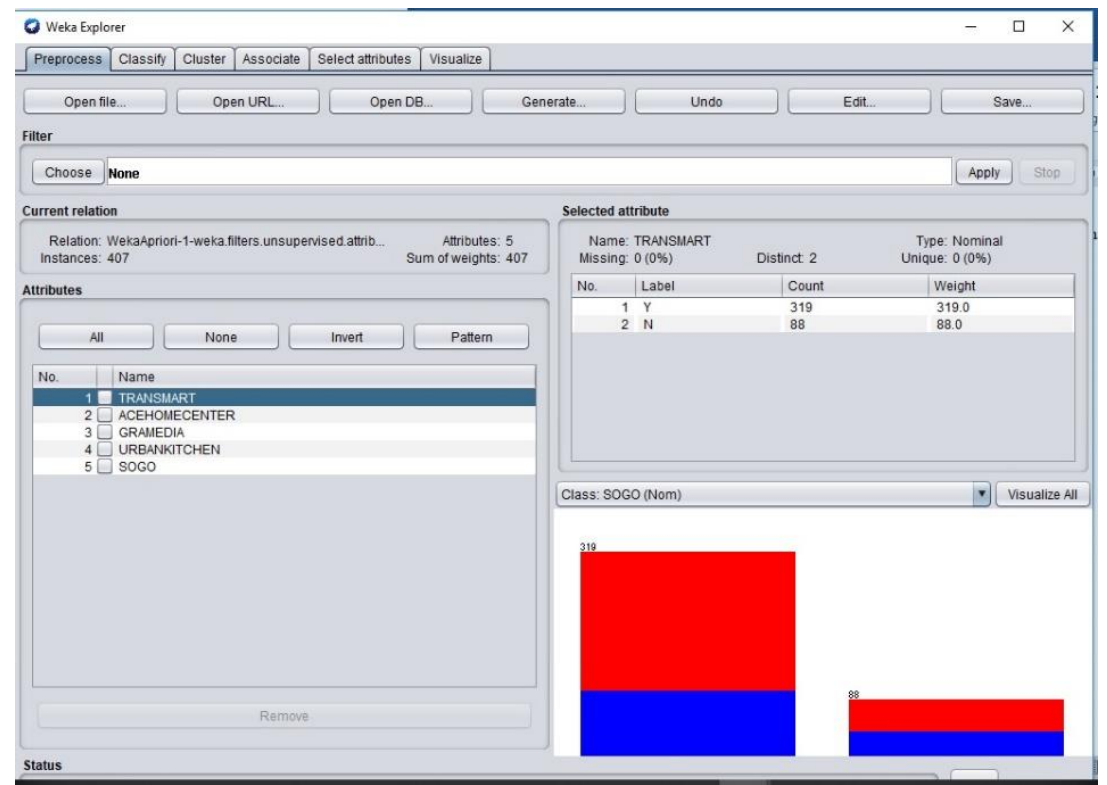

Gambar 3. Implementasi menggunakan aplikasi Weka

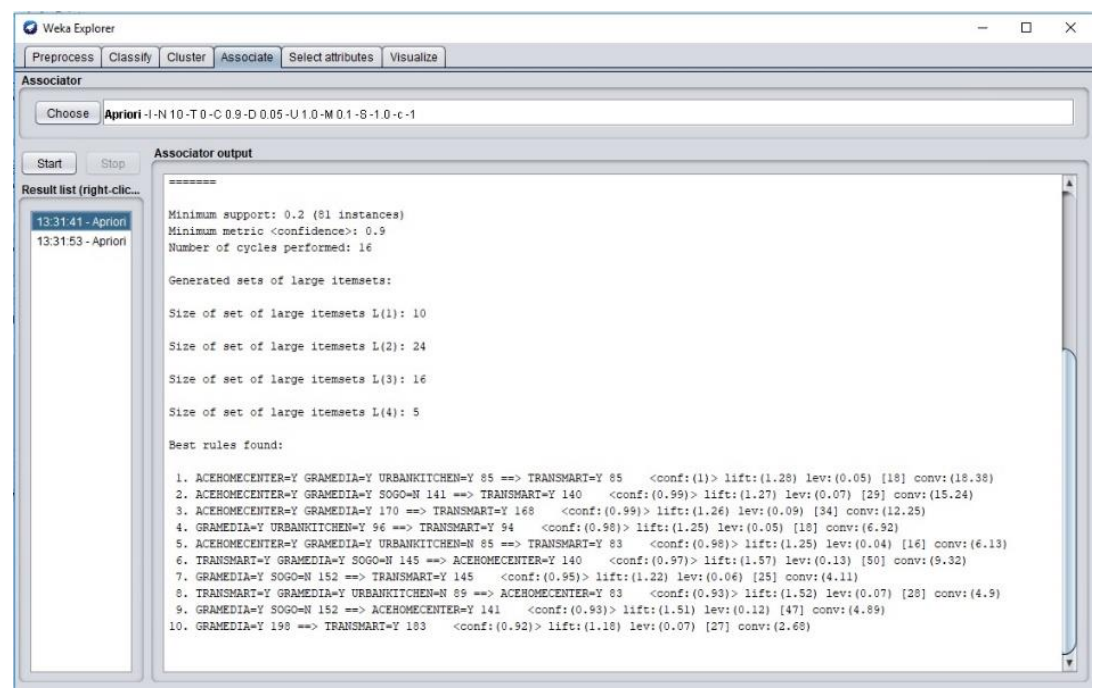

Gambar 4. Hasil pengolahan data menggunakan aplikasi Weka

Dari hasil pengolahan data menggunakan aplikasi Weka, maka didapat hasil sebagai berikut: 


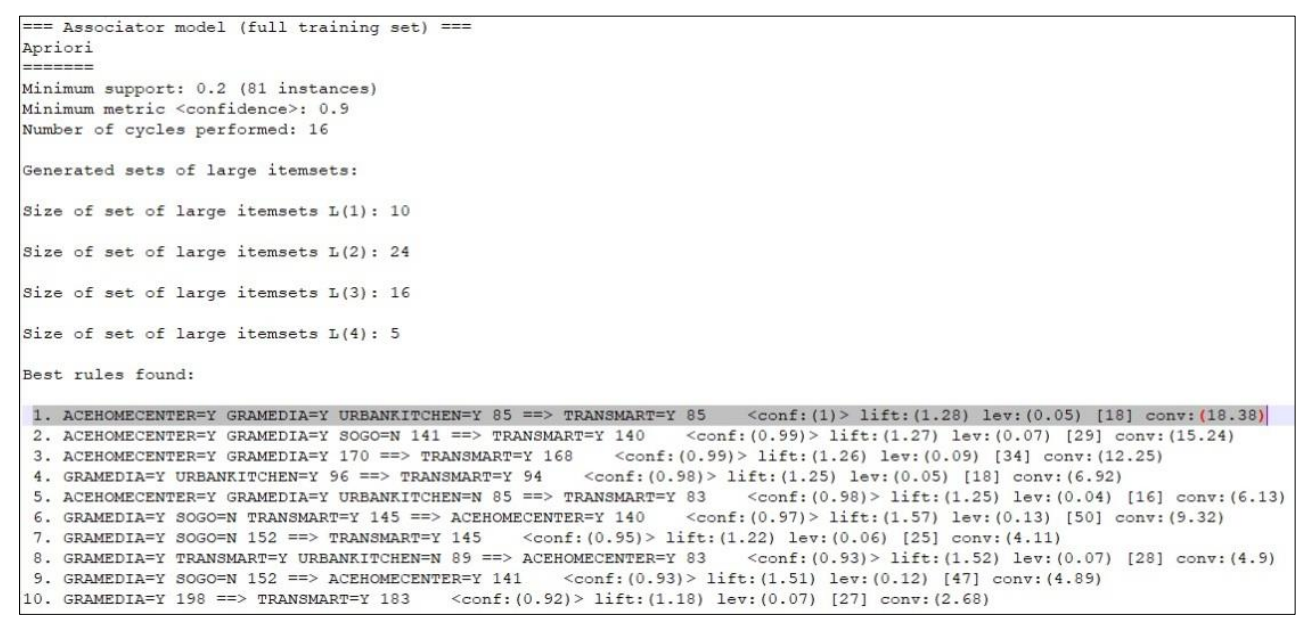

\section{Gambar 5. Hasil pengolahan data menggunakan aplikasi Weka}

Dari data tersebut diatas kita mendapatkan 10 aturan asosiasi dengan nilai confidence yang berbeda. Nilai confidence terbesar didapat pada asosiasi 3 itemset yang menyebutkan bahwa jika terdapat pembelanjaan pada toko Acehomecenter, Gramedia, Urbankitchen maka konsumen akan berbelanja juga di toko Transmart. Sedangkan nilai confidence terbesar untuk 2 itemset menyebutkan bahwa jika konsumen berbelanja di toko Gramedia maka konsumen tersebut juga berbelanja di toko Transmart.

\section{KESIMPULAN DAN SARAN}

Dari penelitian diatas dapat disimpulkan, penggunaan algoritma apriori dapat memetakan memetakan kecenderungan pola belanja konsumen pada periode tertentu. Data yang dihasilkan dapat digunakan oleh pihak pengelola mall maupun pengelola serta pemilik toko untuk menganmbil keputusan seperti:

1. Menentukan lokasi atau area toko yang efektif pada masing masing lantai di dalam mall agar lalu lintas keramaian pengunjung mall dapat merata, sehingga bisa membantu peningkatan penjualan bagi toko yang penjualannya belum optimal.

2. Menentukan promo belanja yang sesuai dengan pola belanja konsumen pada periode yang diinginkan. 
3. Menentukan event yang dapat diselenggarakan di area mall untuk menunjang peningkatan transaksi penjualan.

Saran untuk penelitian berikutnya terkait pola belanja konsumen mall adalah penelitian dapat menggunakan data minimal 1 tahun untuk dapat mendapatkan pola belanja konsumen yang lebih akurat dan dapat di korelasikan dengan pola belanja per bulan bahkan per tahun.

\section{REFERENSI}

Apostolakis, J. (2010). An introduction to data mining. Structure and Bonding. https://doi.org/10.1007/430_2009_1

gsbipb. (2013). Pengertian dan Konsep Data Mining. Retrieved from https://gsbipb.com/?p=821

INFORMATIKALOGI. (2017). Algoritma Apriori (Association Rule). Retrieved from https://informatikalogi.com/algoritma-apriori-association-rule/

Kusrini, E. T. L. (2009). Algoritma Data Mining. In Data Mining.

Larose, D. T. (2005). Discovering Knowledge in Data: An Introduction to Data Mining. In Discovering Knowledge in Data: An Introduction to Data Mining. https://doi.org/10.1002/0471687545

Muchlisin Riadi. (n.d.). Pengertian, Fungsi, Proses dan Tahapan Data Mining. Retrieved from https://www.kajianpustaka.com/2017/09/data-mining.html 